\title{
Comparative Analyses of Modeling Techniques for Cathodic Protection
}

\author{
P. T. Elijah*, M. Obaseki \\ Applied Mechanics and Design/Production Research Group, Department of Mechanical Engineering, Nigeria Maritime \\ University, Okerenkoko, Delta State, NIGERIA.
}

\begin{abstract}
The investigation in this paper provided an outline of the used scientific models for the cathodic protection framework modeling and relatively assessed current modeling strategies. The Technique for Order of Preference by Similarity to Ideal Solution (TOPSIS) investigation was applied in six alternatives and five criteria. Among the criteria, a high criticality was put on the strengths in complex geometries and the unwavering quality of the results. From the study outcomes, it can be established that the best cathodic protection modeling technique considering a number of factors like, the strength in complex geometries like subsea structures, simplicity of use, time allotment required for estimation, industry track record and robustness of the results was the Finite Element Method (FEM) with a score of 0.73 which is a value of relative closeness to the ideal solution of 1 . The second best modeling procedure was Boundary Element Method (BEM) having a value of 0.72, while the least cathodic protection modeling method was analytical models with a TOPSIS score of 0.3372. Regardless of FEM rising as the best cathodic protection modeling technique, the significant detriment related with it is the timeframe required for the estimation. Finally, this research concluded by showing different models performance and comparison made with the numerical results. It is expected that the result of this work will be of significant help for the strengthening of the application of TOPSIS for offshore / subsea engineers.
\end{abstract}

Keywords: TOPSIS, cathodic protection, modeling techniques, FEM, BEM

\section{INTRODUCTION}

In deepwater and subsea operations, the key controlling factors such as seawater temperature, amount of dissolved oxygen, sea current, marine growth and calcareous deposit layers, and the salt level contributes greatly to the onset of corrosion [1]. Mounted Cathodic corrosion protection systems for offshore structure uses are typically complex to estimate and are associated with costintensive maintenance and risks, the mass and size inspection are almost impossible. In essence, corrosion and its management is a highly complicated, time-dependent process associated with high uncertainties and it is becoming increasingly important for offshore structures. Obaseki and Elijah [2], in their study also identified wax deposition as another major challenge in production and transportation of crude oil pipelines in offshore structures as it restrict the oil flow volume and cause unnecessary pressure build-up in pipelines.

Corrosion can be described as the degradation of a metallic material properties and thickness

${ }^{*}$ Corresponding author (Tel: $+234(0) 706164$ 9506)

Email addresses: paul.elijah@nmu.edu.ng (P. T. Elijah), obaseki@nmu.edu.ng (M. Obaseki) over time due to environmental effects. It is the usual tendency of a material's elemental makeup to return to their most thermodynamically natural stable state [3, 4]. Solid particles leads to corrosion of materials via cavitation erosion, liquid impact erosion as well as solid particles erosion which are caused by repeated action of dynamic loads on small area of exposed materials $[2,5,6]$. This loading may last only few microseconds or even nanoseconds with high local-impact pressure of GPa.

The aim of cathodic protection framework modeling is to appraise the appropriation of electrical potential, and protection current density on the electrode surfaces, together with the associated points in or on the electrolyte [3, 7, 8]. Analytical models utilized in designing of the cathodic protection system can generally be classified into two types: The first type depends on Ohm's law and Kirchhoff's laws $[9,10]$. These kinds of models are extremely straightforward for application, however comes with some impediments. One of them is by representing the cathodes basically by resistors, the current density at each point on the electrode surface is gotten as a constant. Also, the polarization impacts of the cathodic protection framework cannot be represented with straightforward components [11-13]. 
The second kind of analytical models depends on estimating the stationary current field by finding the solution of Laplace partial differential equation (LPD) utilizing analytical techniques like variable separation, getting solutions as infinite series, superposition strategy, confident mapping technique and others. The utilization of this methodology is constrained to more straightforward geometries with high level of symmetry $[8,12]$.

Finite element technique is among the commonly and widely utilised numerical techniques in applied science and technology. It is known for sophistication, measured quality and multidisciplinary. The finite element method is algorithmic and moderately easy to program for general expressions of electromagnetic fields [8, 14]. However, this method has one detriment when modeling the Cathodic protection system of underground flow lines because of the necessity for discretization of the entire domain (electrolyte) taken as a semi-infinite area and because of a huge contrast in the sub domain measurements (electrolyte as a semi-infinite sub domain and, for instance, the pipeline surface thickness). One of the most effective methods for taking care of issues in the field of use of cathodic protection frameworks is the boundary element technique. The fundamental merit of this technique is that discretization is needed distinctly at the boundary of the domain of intrigue and there is no requirement for discretization of infinite boundaries [15-18].

As the most appropriate technique for ascertaining the variables of the cathodic protection system of underground metallic facilities, this technique has become more sophisticated during the most recent three decades via hybridization with other mathematical techniques. As a result, it has been utilized for explicit computations in the use of the cathodic protection framework.

Despite the fact that the boundary element method is one of the most utilized techniques for the modeling of the cathodic protection framework, it hardly gives acceptable outcomes for exceptionally long electrode surfaces. This is because the technique considers the electrode systems as equipotential.

So as to quicken the computation of the dispersion of electromagnetic fields, more consideration has been given to meshless numerical techniques. Santos et al. [19-21] utilised the technique of fundamental solutions together with the genetic algorithm (GA) to take care of the issue of dispersion of the current density and electric potential on the electrode surfaces of the cathodic protection framework. The technique of fundamental solutions is relevant, when the fundamental solutions of the field partial differential expressions can be ascertained. The merit of technique of fundamental solutions over the boundary element method is that it does not need any extraordinary incorporation or any exceptional treatment of singular points. The fundamental impediment of this method is in ascertaining the location of virtual sources and the associated current density. Be- cause of the nonlinearity of boundary conditions, it is important to apply iterative methods together with the method of fundamental solutions.

At the moment, a number of analytical model and models dependent on numerical techniques used for computations when configuring and executing cathodic protection frameworks have been proposed. However, little studies has been conducted on their unbiased comparison with the utilization of TOPSIS. Thus, the purpose of this paper is to comparatively investigate the different analytical and numerical techniques for the computation of the electrical potential and current density dispersion for cathodic protection framework utilizing TOPSIS.

\section{METHODOLOGY \\ Modeling Techniques}

The investigation of the cathodic protection modeling techniques were carried out with a multi-criteria analysis strategy utilising the "Technique for Order Preference by Similarity to Ideal Solution (TOPSIS)". The modeling methods compared were: the analytical models and numerical models (Finite Difference Method (FDM), Finite Element Method (FEM), Boundary Element Method (BEM), Coupled Boundary Element and Finite Element Method (CBDFEM) and Meshless Methods (MM)). These modeling methods were analyzed and compared based on certain criteria, which comprised: the application in complex geometries like subsea structures, ease of application, length of time needed for calculation, industry track record and reliability of the results.

\subsection{Technique of Order Preference by Simi- larity to Ideal Solution (TOPSIS)}

The TOPSIS technique lies on the fact that the optimum option should have the least geometric distance from the positive ideal alternative and the farthest geometric distance from the negative ideal alternative [22]. It analyzes a set of options by assigning weights on each factor for comparison, normalizing the weights for each factor and computing the geometric distance between each option and the ideal positive alternative. TOPSIS assumed the factors are monotonically increasing or decreasing [23]. Normalization is usually needed because the factors are quite unharmonious which is common in a multi-criteria problem. TOPSIS allows for trade-off between the criteria, where a negative outcome in one criteria can be cancelled out by a positive outcome in another criteria [24]. This offers a more realistic form of modeling and comparative analysis.

TOPSIS considers three sets of attributes or criteria: Qualitative benefit attributes, Quantitative benefit attributes and Cost attributes.

With TOPSIS two artificial options are hypothesized as ideal alternative; the one with the best attribute values, and negative ideal solution; the one with the worst attribute values.

TOPSIS chooses the option that is closest to the ideal solution and farthest from negative ideal solution [25]. 


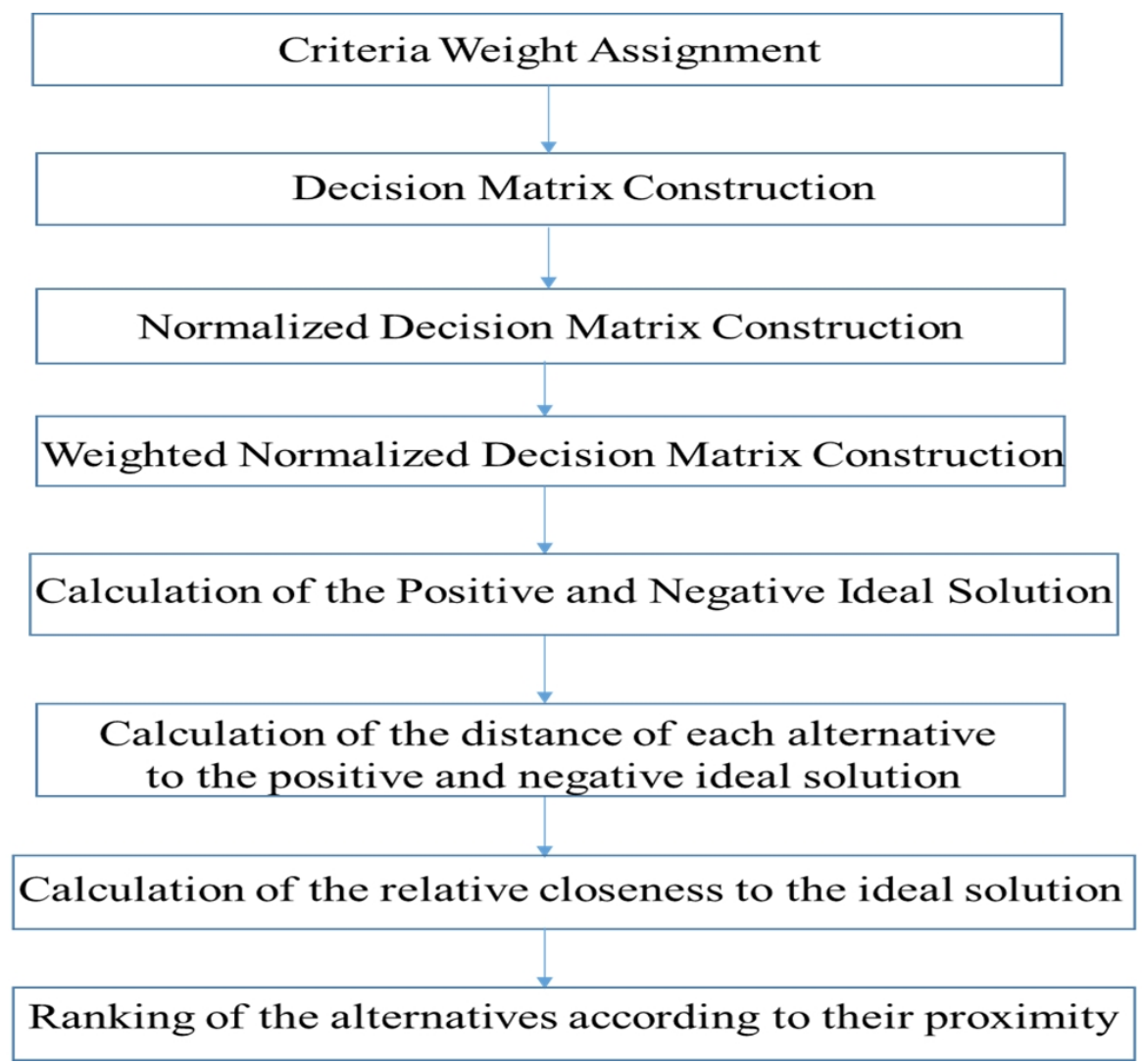

Figure 1: TOPSIS Algorithm.

2.1.1.

TOPSIS takes into consideration $\mathrm{m}$ number of alternatives to choose from and $\mathrm{n}$ criteria to base the choice on and one must score each option against the corresponding criterion. Assume $x_{i j}$ score of alternative $i$ with respect to criterion $j$, a matrix $\mathrm{X}=\left(x_{i} \mathrm{j}\right) \mathrm{m} \times \mathrm{n}$ matrix is formed. $J$ is the set of positive attributes (the more the better) and $J^{\prime}$ is the set of negative attributes (the less the better). Each factor can be assigned certain points on a scale of $0-10$ or $0-100$ by the experts [22].

\section{Steps for TOPSIS [25]}

Step 1: Construct a normalized decision matrix. This step converts a number of attribute dimensions into dimensionless attributes, which allows for comparisons across criteria. The weights or scores can be normalized using the formula below:

$$
r_{i j}=\frac{x_{i j}}{\left(\sum x_{i j}^{2}\right)^{\frac{1}{2}}} \text { for } i=1 \ldots m ; j=1 \ldots n
$$

Step 2: Construct the weighted normalized decision matrix. With specific weights for individual attribute wj for $\mathrm{j}=1 \ldots \mathrm{n}$. Individual column of the normalized decision matrix is multiplied by its corresponding weight. A component of the new matrix is framed thus:

$$
v_{i j=w_{j}} w_{j}
$$

Step 3: Estimate the ideal and negative ideal alternatives.
- Ideal alternative.

$$
\begin{gathered}
A^{*}=\left\{v_{1}^{*} \ldots v_{n}^{*}\right\} \\
d v_{j}^{*}=\left\{\max \left(v_{i j}\right) \text { if } j \in J ; \min \left(v_{i j}\right) \text { if } j \in J\right\}
\end{gathered}
$$

- Negative ideal alternative

$$
A^{\prime}=\left\{v_{1}^{\prime} \ldots v_{n}^{\prime}\right\}
$$

where

$$
v^{\prime}=\left\{\max \left(v_{i j}\right) \text { if } j \in J ; \min \left(v_{i j}\right) \text { if } j \in J^{\prime}\right\}
$$

Where $v$ is an element of the new matrix and $A$ is the alternative

Step 4: Estimate the separation measures for each alternative.

The separation from the ideal solution is represented thus:

$$
S_{i}^{\prime}=\left[\sum\left(v_{j}^{*}-v_{i j}\right)^{2}\right]^{\frac{1}{2}} i=1 \ldots m
$$

In the same manner, the separation from the negative ideal solution is represented thus:

$$
S_{i}^{\prime}=\left[\sum\left(v_{j}^{\prime}-v_{i j}\right)^{2}\right]^{\frac{1}{2}} i=1 \ldots m
$$


Step 5: Estimate the relative closeness to the ideal alternative $C_{i}^{*}$

$$
C_{i}^{*}=\frac{S_{i}^{\prime}}{\left(S_{i}^{*}+S_{i}^{\prime}\right)}, 0<C_{i}^{*}<1
$$

Select the option with $C_{i}^{*}$ closest to 1 .

Step 6: Rate the preference order.

\section{RESULTS AND DISCUSSIONS (TOPSIS Comparative Analysis)}

Utilizing TOPSIS to the paper, $\mathrm{m}=6$ alternatives/options Analytical models (AM), Finite Difference Method (FDM), Finite Element Method (FEM), Boundary Element Method (BEM), Coupled Boundary Element and Finite Element Method (BD/FEM) and Meshless Methods (MM)). $\mathrm{n}=5$ attributes/criteria including the applicability in complex geometries like subsea structures, ease of application, length of time needed for calculation, industry track record and reliability of the results. $w_{j}=$ set of weights for each criteria as shown in Table 1. $x_{i j}=$ score of option i with respect to criterion $j$ as shown in Table $2 . J=$ set of benefit attributes: applicable in complex geometries, ease of application, less time needed for calculation, proven industry track record and highly reliable results.

Table 1: Assigned weight to the criteria.

\begin{tabular}{lc}
\hline Criteria & Weight \\
\hline Applicability in complex geometries & 0.9 \\
Ease of application & 0.6 \\
Time needed for calculation & 0.6 \\
Industry track record & 0.7 \\
Reliability of result & 0.9 \\
\hline
\end{tabular}

RATING SCALE: Scale of 1 (1 implies very important, 0 means not important)

Analytical models are simpler in application, but does not yield a reliable result and cannot be used for real on the field cathodic protection systems and complex geometries [11, 12]. The finite difference method has a proven record of accomplishment, as it has been used since the early seventies; it also yields an accurate result. However, it is rarely used because of the longer time needed for calculations. The finite element is easier to use, it is one of the most frequently used, suitable for complex structures due to its robustness. It has a proven record of accomplishment in the industry, but its major shortcomings is that it requires a longer time for calculation.

For the boundary element method, it is very efficient for complex structures, yields reliable results, has a proven track record as it has been in use for over three decades. However, it also requires a longer time for calculation, but not as long as the FEM and FDM.

The Coupled boundary element/finite element technique. This is user friendly, and has been among the commonly and widely utilised techniques. However, it does not yield satisfactory results in some cases. The Meshless method is very suitable for complex structures and it is very simple to use. However, it is not a developed modeling technique. It gained its first application in 2012 [19-21]. In addition, it requires a long time for calculation. These merits and demerits of the models guided the scores assigned to the alternatives against specific criteria.

The normalized decision matrix $r_{i j}=x_{i j} /\left(\sum x_{i j}^{2}\right)^{\frac{1}{2}}$ shown in Tables 3 and 4 . The weighted normalized decision matrix $v_{i j}=w_{j} r_{i j}$ was developed by multiplying each column of the normalized decision matrix (Table 5) by its associated weight (Table 1 ).

A set of maximum values for each criteria (from Table 5) also known as the ideal solution $A^{*}=$ $\left\{v_{1}^{*} \ldots v_{n}^{*}\right\}$ is developed as shown under step 3. Similarly, a set of minimum values for each criteria (from Table 5) also known as the Negative ideal solution $A^{\prime}=\left\{v_{1}^{\prime} \ldots v_{n}^{\prime}\right\}$ was developed as shown in step 3.

The separation from the ideal alternative is, $S_{i}^{*}=\left[\sum\left(v_{j}^{*}-v_{i j}\right)^{2}\right]^{\frac{1}{2}}$ is computed as shown in table 6 and the results are shown under step 4a. In the same manner, the separation from the negative ideal alternative $S_{i}^{\prime}=\left[\Sigma\left(v_{j}^{\prime}-v_{i j}\right)^{2}\right]^{\frac{1}{2}}$ is estimated as shown in table 7 and the results are displayed under step $4 b$.

Finally, the relative closeness to the ideal solution $C_{i}^{*}=S_{i}^{\prime} /\left(S_{i}^{*}+S_{i}^{\prime}\right)$ is computed and the results shown in Table 8.

Figure 2 shows the weights assigned to each of the criterion on a scale of $0-1$ based on their importance to the analysis.

The options analysed comprised:

Option 1: AM (Analytical models); Option 2: FDM (Finite difference method); Option 3: FEM (Finite element method); Option 4: BEM (Boundary element method); Option 5: Coupled BE/FEM (Coupled boundary element/finite element method) and Option 6: MM (Meshless Methods).The decision matrix for the options rating is shown in Table 2:

With TOPSIS, we have:

Step 1: Standardizing the decision matrix This step makes the ratings dimensionless by dividing each column of the decision matrix by root sum of square of respective rows. The result of this is shown in Table 3 and Fig. 3:

Figure 3 depicts the dimensionless ratings of Table 3.

Step 1 (b): divide each column by $\left(\sum x_{i j}^{2}\right)^{\frac{1}{2}}$ to get $r_{i j}$ which is the normalized decision matrix as shown in Table 4.

Step 2: Develop weighted standardized decision matrix by multiplying the criteria weight 
Table 2: Score of option i with respect to criterion $j\left(x_{i j}\right)$.

Criteria

Application in complex geometries

Ease of application

Less time needed for calculation

Proven industry tract record

Reliability of result
AM FDM FEM BEM COUPLED BE/FEM MM

\begin{tabular}{llllll}
3 & 6 & 8 & 9 & 6 & 8 \\
9 & 4 & 8 & 4 & 8 & 7 \\
6 & 3 & 3 & 5 & 6 & 5 \\
6 & 9 & 8 & 8 & 8 & 5 \\
3 & 8 & 9 & 9 & 3 & 7 \\
\hline
\end{tabular}

RATING SCALE: Scale of 10 (10 implies excellent, 1 means very poor)

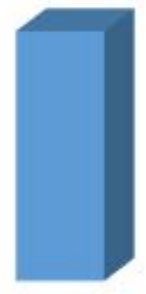

Ease of application

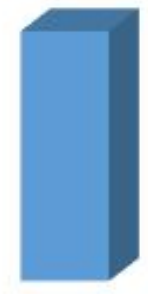

Time needed for calculation

CRITERIA

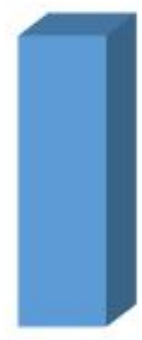

Industry track record

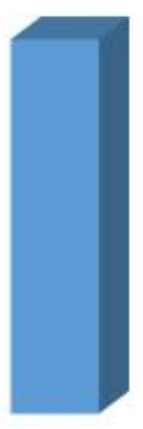

Reliability of result

Figure 2: Weight Vs Criteria.

Table 3: Computation of $\left(\sum x_{i j}^{2}\right)^{\frac{1}{2}}$

\section{CRITERIA}

- Applicable in complex geometries Ease of application

Less time needed for calculation
AM FDM FEM BEM COUPLED BE/FEM

$\begin{array}{ll}8 & 9 \\ 8 & 4 \\ 3 & 5\end{array}$

$\begin{array}{ll}9 & 6 \\ 4 & 8 \\ 5 & 6\end{array}$

6
8

6
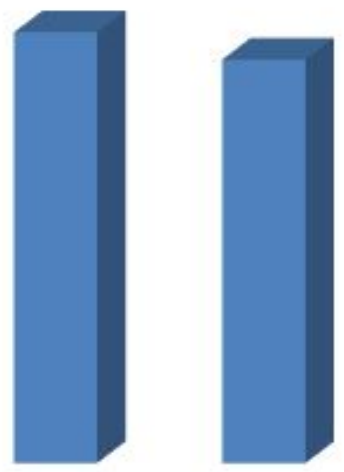

Proven Industry track record

Reliability of result

CRITERIA

Figure 3: Standardized Values Vs Criteria . 
Table 4: The normalized decision matrix $\left(r_{i j}=x_{i j} /\left(\sum x_{i j}^{2}\right)^{\frac{1}{2}}\right)$

Criteria

Applicable in complex geometries

Ease of application

Less time needed for calculation

$\begin{array}{cccccc}\text { AM } & \text { FDM } & \text { FEM } & \text { BEM } & \text { COUPLED BE/FEM } & \text { MM } \\ 0.176 & 0.352 & 0.47 & 0.528 & 0.352 & 0.47 \\ 0.528 & 0.235 & 0.47 & 0.235 & 0.47 & 0.411 \\ 0.507 & 0.254 & 0.254 & 0.423 & 0.507 & 0.423\end{array}$

Table 5: The weighted normalized decision matrix $v_{i j}=w_{j} r_{i j}$

\section{Criteria}

Applicable in complex geometries

Ease of application

Less time needed for calculation
AM FDM FEM BEM COUPLED BE/FEM MM

$\begin{array}{lllll}0.158 & 0.317 & 0.423 & 0.475\end{array}$

$\begin{array}{lllll}0.317 & 0.141 & 0.282 & 0.141\end{array}$

$\begin{array}{llll}0.304 & 0.152 & 0.152 & 0.254\end{array}$

0.317

0.282

0.304

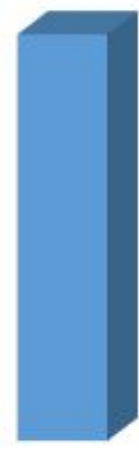

Less time needed Proven Industry for calculation track record

Reliability of result

CRITERIA

Figure 4: Ideal Alternative Values Vs Criteria.

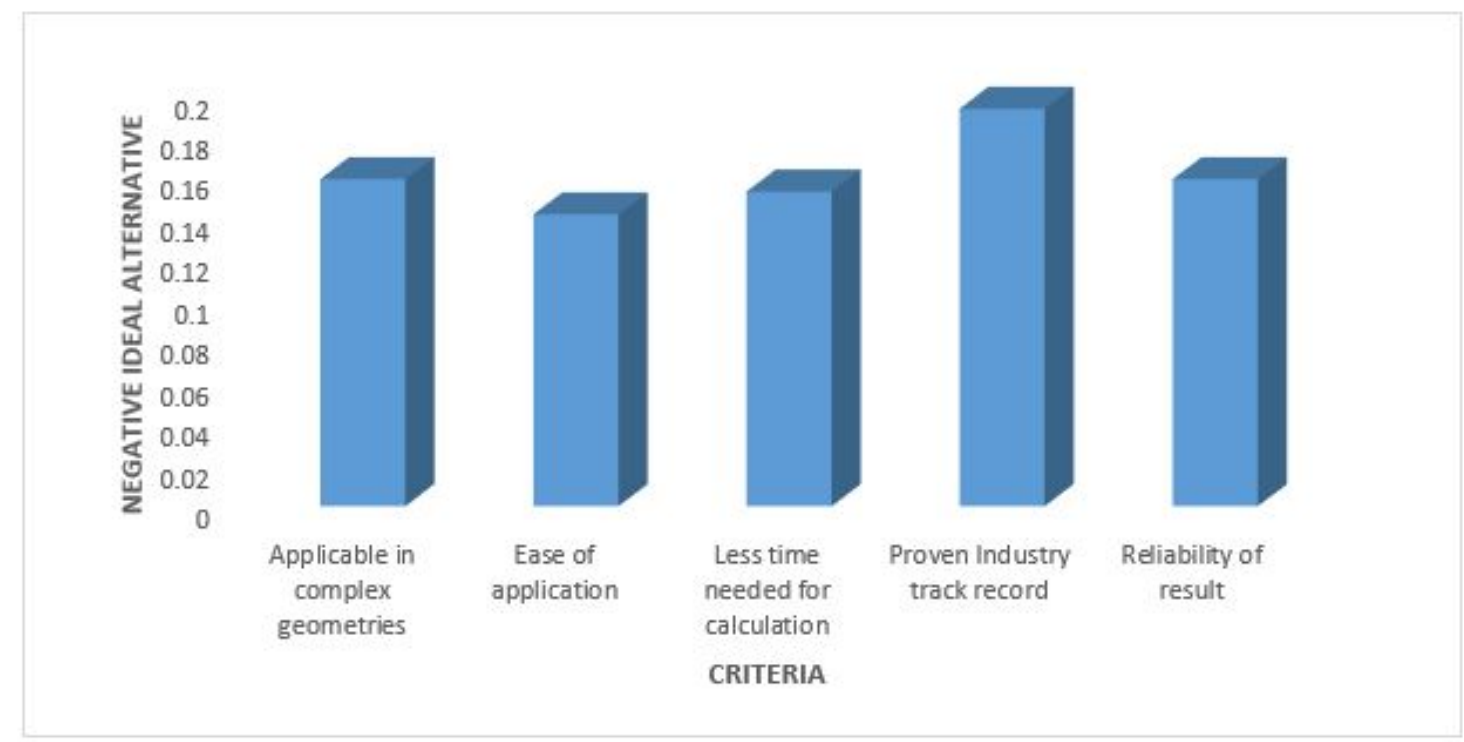

Figure 5: Negative Ideal Alternative Values Vs Criteria. 
Table 6: Results of the computation of the separation from ideal alternative $S_{i}^{*}=\left[\Sigma\left(v_{j}^{*}-v_{i j}\right)^{2}\right]^{\frac{1}{2}}$

\begin{tabular}{lcccccc}
\hline Criteria & AM & FDM & FEM & BEM & COUPLED BE/FEM & MM \\
Applicable in complex geometries & 0.1 & 0.025 & 0.0027 & 0 & 0.025 & 0.0027 \\
Ease of application & 0 & 0.031 & 0.001225 & 0.031 & 0.001225 & 0.0049 \\
Less time needed for calculation & 0 & 0.023 & 0.023 & 0.0025 & 0 & 0.0025 \\
Proven Industry track record & 0.013 & 0 & 0.00137 & 0.00137 & 0.00137 & 0.023 \\
\hline
\end{tabular}

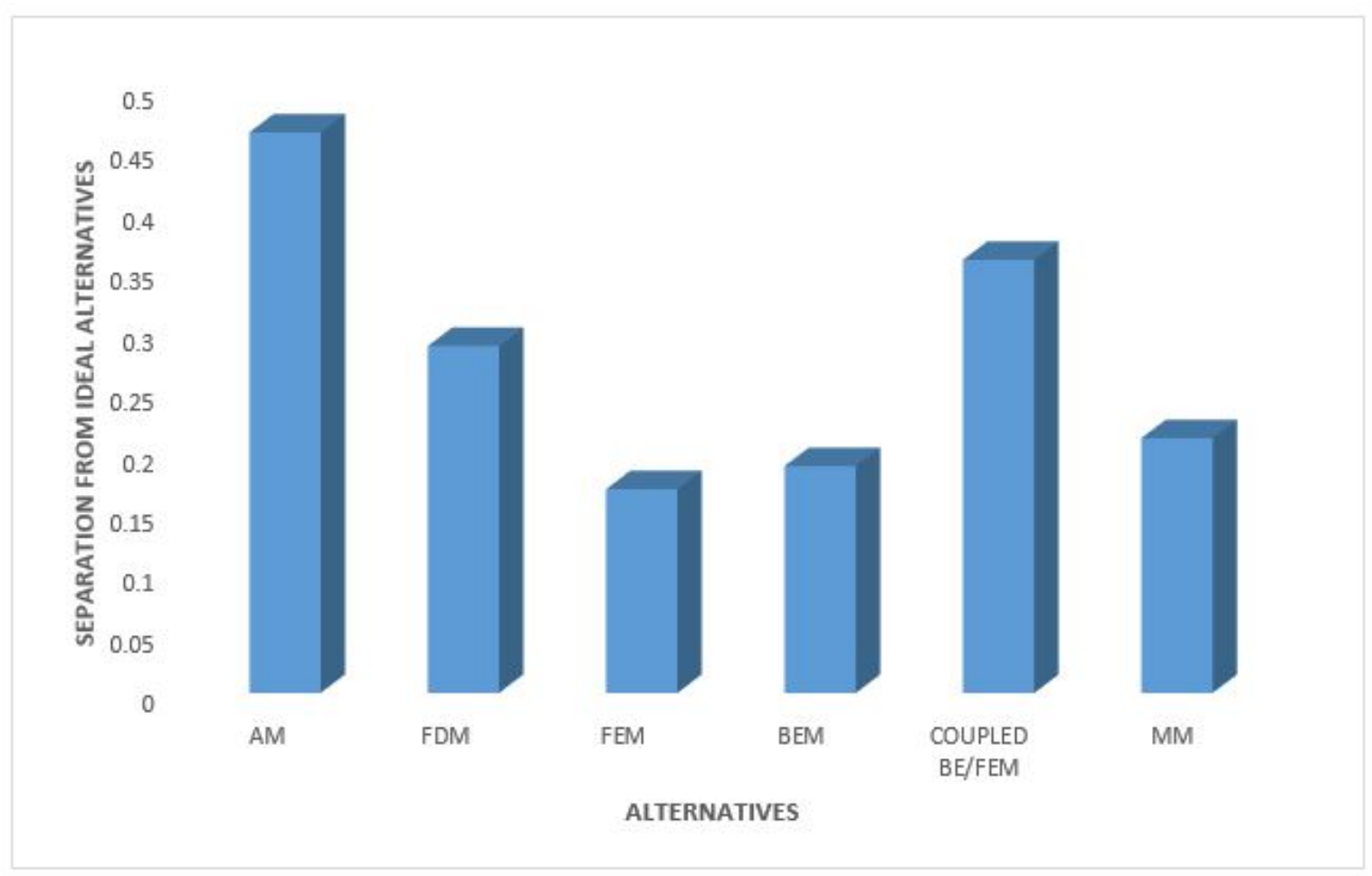

Figure 6: Separation from Ideal Alternative Vs Alternatives.

Table 7: Results of the computation of separation from the negative ideal alternative, $S_{i}^{\prime}=\left[\Sigma\left(v_{j}^{\prime}-v_{i j}\right)^{2}\right]^{\frac{1}{2}}$

\begin{tabular}{lcccccc}
\hline Criteria & AM & FDM & FEM & BEM & COUPLED BE/FEM & MM \\
\hline Applicable in complex geometries & 0 & 0.0253 & 0.07 & 0.1005 & 0.0253 & 0.07 \\
Ease of application & 0.031 & 0 & 0.02 & 0 & 0.02 & 0.01124 \\
Less time needed for calculation & 0.023 & 0 & 0 & 0.0104 & 0.023 & 0.0104 \\
Proven Industry track record & 0.00144 & 0.023 & 0.01323 & 0.01323 & 0.01323 & 0 \\
Reliability of result & 0 & 0.069 & 0.1 & 0.1 & 0 & 0.0441 \\
$S_{i}^{\prime}=\left[\Sigma\left(v_{j}^{\prime}-v_{i j}\right)^{2}\right]^{\frac{1}{2}}$ & $\mathbf{0 . 2 3 5}$ & $\mathbf{0 . 3 4 2 5}$ & $\mathbf{0 . 4 5 1}$ & $\mathbf{0 . 4 7 3}$ & $\mathbf{0 . 2 8 6}$ & $\mathbf{0 . 3 6 8}$ \\
\hline
\end{tabular}

Table 8: Computation and results of the relative closeness to the ideal solution $C_{i}^{*}=S_{i}^{\prime} /\left(S_{i}^{*}+S_{i}^{\prime}\right)$

\begin{tabular}{llllllc}
\hline & AM & FDM & FEM & BEM & COUPLED BE/FEM & MM \\
\hline$S_{i}^{*}$ & 0.462 & 0.286 & 0.168 & 0.187 & 0.357 & 0.21 \\
$S_{i}^{\prime}$ & 0.235 & 0.3425 & 0.451 & 0.473 & 0.286 & 0.368 \\
\hline
\end{tabular}




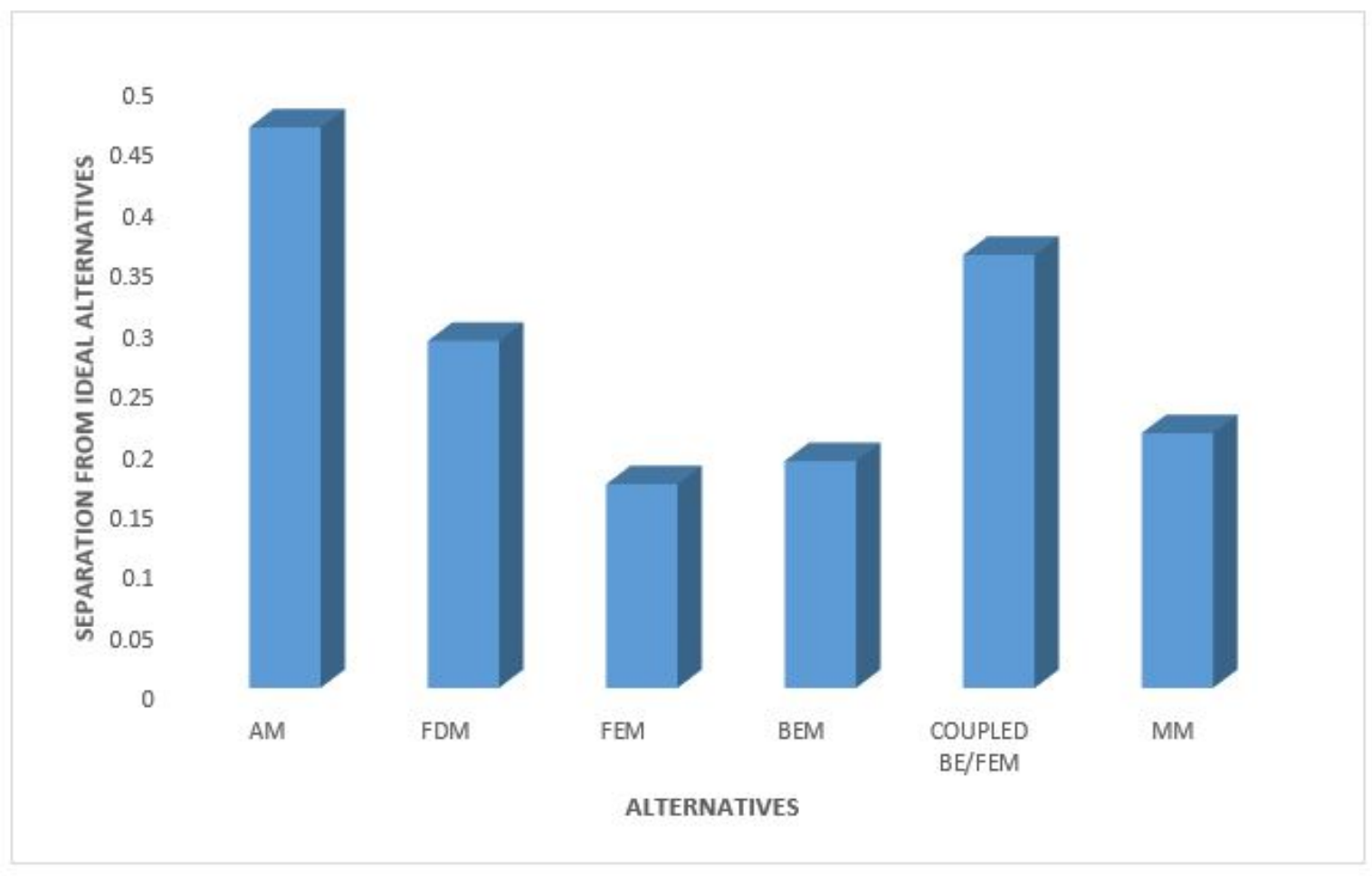

Figure 7: Separation from Ideal Alternative Vs Alternatives.

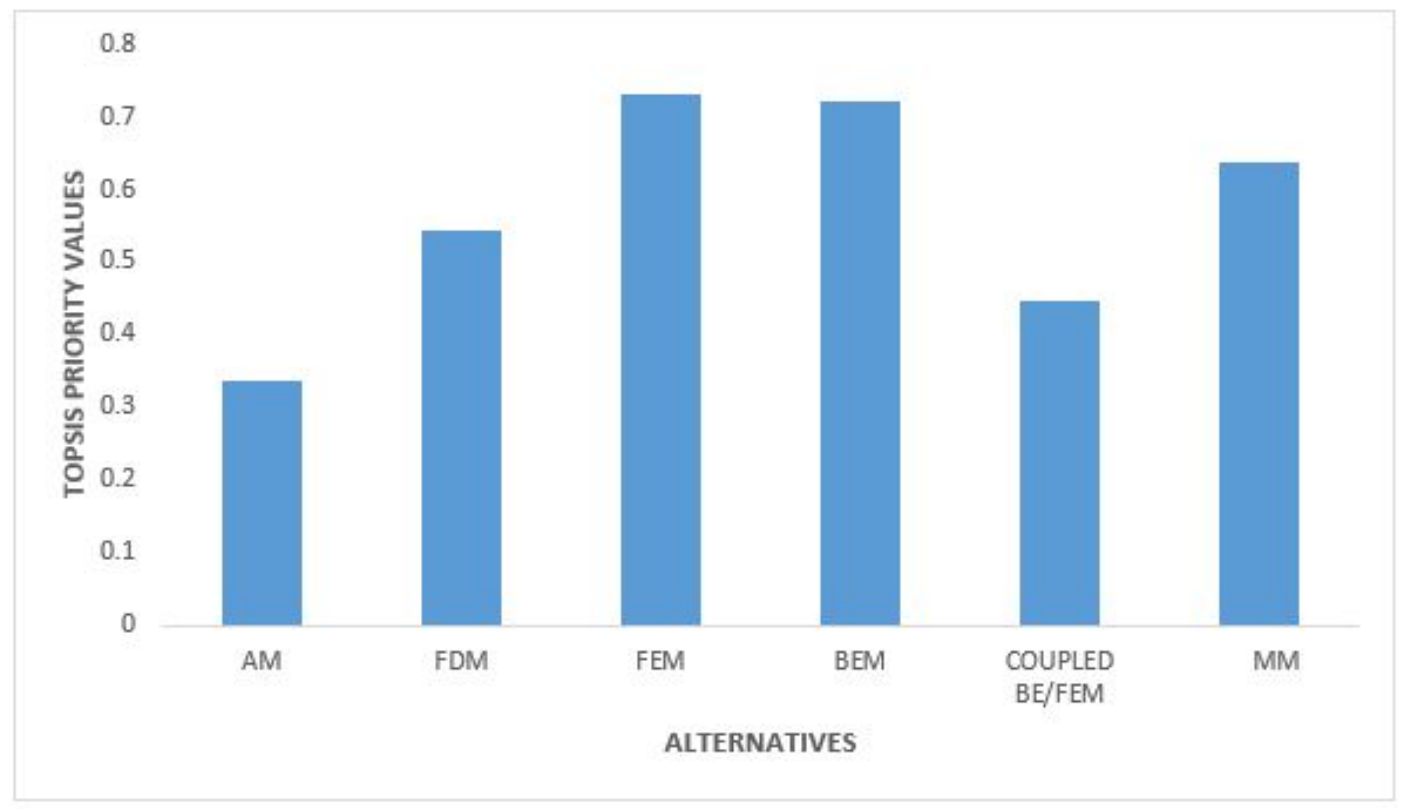

Figure 8: TOPSIS Priority Values Vs Alternatives. 
(see Table 2) with each rating in Table 4 above. The weighted standardized decision matrix is presented in Table 5 below:

Step 3: Estimate ideal solution and negative ideal solution.

The maximum values set for each factor is the ideal solution while the minimum values set for each factor is the negative ideal solution.

Ideal alternative $A^{*}:\{0.475,0.317,0.304,0.344$, $0.473\}$

Figure 4 depicts the maximum values set for each factor from Table 5.

Negative ideal alternative $A^{\prime}:\{0.158,0.141$, $0.152,0.192,0.158\}$

Figure 5 depicts the minimum values set for each factor from Table 5 .

Step 4 (a): Determine separation $S-i_{*}$ from ideal solution $\left(A^{*}\right)$.

$$
S_{i}^{*}=\left[\Sigma\left(v_{j}^{*}-v_{i j}\right)^{2}\right]^{\frac{1}{2}} \text { for individual column. }
$$

These results of this computation are tabulated in Table 6.

$$
S_{i}^{*} \quad=\quad\left[\Sigma\left(v_{j}^{*}-v_{i j}\right)^{2}\right]^{\frac{1}{2}}
$$

$\{0.462,0.286,0.168,0.187,0.357,0.21\}$

Figure 6 depicts how the alternatives scored against each other with respect to the separation from ideal alternatives score

Step 4 (b): Estimate separation from negative ideal alternative $\left(A^{\prime}\right)$ and $S_{i}^{\prime}=\left[\Sigma\left(v_{j}^{\prime}-v_{i j}\right)^{2}\right]^{\frac{1}{2}}$ for individual column as depicted in Table 7.

$$
S_{i}^{\prime} \quad \quad \quad\left[\sum\left(v_{j}^{\prime}-v_{i j}\right)^{2}\right]^{\frac{1}{2}}
$$

$\{0.235,0.3425,0.451,0.473,0.286,0.368\}$

Figure 7 illustrates the values of the separation from negative ideal solution for each of the alternatives.

Step 5: Calculate the relative closeness to the ideal solution $C_{i}^{*}=S_{i}^{\prime} /\left(S_{i}^{*}+S_{i}^{\prime}\right)$.

The matrix of the closeness to the ideal solution is provided in the Table 8 below:

Figure 8 shows the TOPSIS rating for each of the alternatives.

Therefore, the best cathodic protection modeling method considering the several factors including: the applicability in complex geometries like subsea structures, ease of application, length of time needed for calculation, industry track record and reliability of the results, having performed all the TOPSIS steps over these five criteria is Finite element method (FEM) with a TOPSIS score of 0.73 while the least cathodic protection modeling method is Analytical models with a TOPSIS score of 0.3372 . Tables 1 and 2 were developed majorly based on expert judgement. In this analysis, great importance was placed more on the applicability of the modeling methods in complex geometries and the reliability of results, followed by the industries track record. Factors like time needed for calculation and ease of application has the least importance, and therefore the lowest weight assigned to them. The low values obtained for Analytical methods, Coupled Boundary Element and Finite Element Method, and the Finite Difference Method are attributed to these placed importance and assigned weights on the criteria.

\section{CONCLUSIONS}

The understanding of cathodic protection is important. In this study, the investigation provided an outline of used scientific models for cathodic protection framework modeling and relatively assessed current modeling strategies. Having performed the complete TOPSIS steps over five criteria, the results of this work revealed the following:

1. Finite element method (FEM) which scored 0.73 (which is a good value of relative closeness to the ideal solution of 1) whereas an analytical model was the least method with a TOPSIS scores of 0.3372 .

2. From the TOPSIS analysis, the second best modeling method is the boundary element method, having a value of 0.72 . It is good to note that, despite Finite element method emerging as the best cathodic protection modeling method, the major disadvantage associated with it, which is the very long time needed for calculation, has to be addressed.

3. The Meshless method has a great potential to be an efficient cathodic protection modeling method in the future, however, this method still requires further application in the industry. For now, it is still an emerging method. The findings of this research provides better insight for the application of TOPSIS in offshore/subsea engineering.

\section{References}

[1] D. RP-B401, "Cathodic protection design," Recommended Practice, 2010.

[2] M. Obaseki and P. Elijah, "Dynamic modeling and prediction of wax deposition thickness in crude oil pipelines." Journal of King Saud University Engineering-Sciences, 2020.

[3] I. Turković, "Contribution to the study of the influence of nonlinear distribution of voltage and current on the optimization of protective lengths in the domain of cathodic protection (in bosnian)," Ph.D. dissertation, Sarajevo, 2010

[4] M. Obaseki, "Development of twelve parameter prediction model for examining the under-pipe corrosion deposit condition localized carbon steel in acidic medium." J. Appl. Sci. Environ. Manage. (JASEM), vol. 23, no. 6 , pp. 1021-1027, 2020.

[5] M. Obaseki, P. Elijah, and G. Ayetan, "Modeling the concentration of wax in crude oil with time and pipe length, International Journal of Maritime and Interdisciplinary Researches, vol. 1, no. 1, pp. 202-211, $2020 \mathrm{a}$.

[6] M. Obaseki, P. Elijah, and P. Alfred, "Development of model to eliminate sand trapping in horizontal fluid pipelines," Journal of King Saud University Engineering- Sciences, $2020 \mathrm{~b}$

[7] V. DeGiorgi, "Corrosion basics and computer modeling," Industrial applications of the boundary element method, Computational Mechanics, pp. 47-79, 1993.

[8] D. Riemer, "Modeling cathodic protection for pipeline networks," Ph.D. dissertation, niversity of Florida, Gainesville, FL, 2012. 
[9] J. H. Morgan, Cathodic Protection, 2nd ed. Houston: NACE, 1993.

[10] R. Corbett, "Cathodic protection as an equivalent electrical circuit," IEEE Transactions on Industry Applications, vol. 6, pp. 1533-1537, 1985.

[11] L. Freiman, "On the insulation resistance of an underground pipeline polarization component and total resistance," Protection of Metals, vol. 37, no. 3, pp. 268-279, 1985.

[12] S. Martinez and I. Štern, "A mathematical model for the internal cathodic protection of cylindrical structures by wire anodes," Journal of Applied Electrochemistry, vol. 30, no. 9, pp. 1053-1060, 2000).

[13] V. Cicek, Cathodic Protection - Industrial solutions for protection against corrosion. Wiley, 2013.

[14] R. Adey and P. Hang, "Computer simulation as an aid to corrosion control and reduction," in NACE Corrosion Conference, USA, Texas, San Antonio, 1999.

[15] R. Adey, S. Niku, C. Brebbia, and J. Finnegan, "Computer aided design of cathodic protection system," $A p$ plied Ocean Research, vol. 8, no. 4, pp. 209-222, 1986.

[16] S. Martinez, "Evaluation of the uniform current density assumption in cathodic protection system with close anode to cathode arrangement," Materials and Corrosion, vol. 61, no. 4, pp. 338-342, 2010.

[17] N. Zamani, J. Chuang, and J. Porter, "Bem simulation of cathodic protection systems employed in infinite electrolytes," International Journal for Numerical Methods in Engineering, vol. 24, pp. 605-620, 1997.

[18] A. Mujezinović, A. Muharemović, I. Turković, and A. Muharemović, "Calculation of the protective current density distribution of a cathodic protection system with galvanic anodes in terms of double-layer electrolyte," in International conference on Boundary Elements Method and Other Reduction Methods, $B E M / M R M$, Croatia, 2012.

[19] W. Santos, J. Santiago, and J. Telles, "An application of genetic algorithms and the method of fundamental solutions to simulate cathodic protection systems," Computer Modeling in Engineering and Sciences (CMES), vol. 87, no. 1, pp. 23-40, 2012.

[20] - "Optimal positioning of anodes and virtual sources in the design of cathodic protection systems using the method of fundamental solutions," Engineering Analysis with Boundary Elements (EABE), vol. 46, pp. 67-74, 2014

[21] _ "Using the gaussian function to simulate constant potential anodes in multi objective optimization of cathodic protection systems," Engineering Analysis with Boundary Elements (EABE), vol. 73, pp. 35-41, 2016.

[22] A. Assari, T. Mahesh, and E. Assari, "Role of public participation in sustainability of historical city: usage of topsis method," Indian Journal of Science and Technology, vol. 5, no. 3, pp. 2289-2294, 2012.

[23] I. Beg and T. Rashid, "Group decision making using intuitionistic hesitant fuzzy sets." International Journal of Fuzzy Logic and Intelligent Systems, vol. 14, no. 3, pp. 181-187, 2014.

[24] R. Greene, R. Devillers, J. Luther, and B. Eddy, "Gisbased multi-criteria analysis," Geography Compass, vol. 5, no. 6 , pp. $412-432,2011$.

[25] E. Zavadskas, A. Zakarevicius, and J. Antucheviciene, "Evaluation of ranking accuracy in multi-criteria decisions," Informatica, vol. 17, no. 4, pp. 601-618, 2006. 